\title{
The Hand Sees Visual Periphery Better Than the Eye: Motor-Dependent Visual Motion Analyses
}

\author{
Hiroaki Gomi, ${ }^{1,3}$ Naotoshi Abekawa, ${ }^{1}$ and Shinsuke Shimojo ${ }^{2,3}$ \\ ${ }^{1}$ NTT Communication Science Laboratories, Nippon Telegraph and Telephone Corporation, Morinosato, Atsugi, Kanagawa 243-0198, Japan, ${ }^{2}$ Division of \\ Biology, California Institute of Technology, Pasadena, California 91125, and ${ }^{3}$ CREST, Japan Science and Technology, Kawaguchi, Saitama 332-0012, Japan
}

Information pertaining to visual motion is used in the brain not only for conscious perception but also for various kinds of motor controls. In contrast to the increasing amount of evidence supporting the dissociation of visual processing for action versus perception, it is less clear whether the analysis of visual input is shared for characterizing various motor outputs, which require different kinds of interactions with environments. Here we show that, in human visuomotor control, motion analysis for quick hand control is distinct from that for quick eye control in terms of spatiotemporal analysis and spatial integration. The amplitudes of implicit and quick hand and eye responses induced by visual motion stimuli differently varied with stimulus size and pattern smoothness (e.g., spatial frequency). Surprisingly, the hand response did not decrease even when the visual motion with a coarse pattern was mostly occluded over the visual center, whereas the eye response markedly decreased. Since these contrasts cannot be ascribed to any difference in motor dynamics, they clearly indicate different spatial integration of visual motion for the individual motor systems. Going against the overly unified hierarchical view of visual analysis, our data suggest that visual motion analyses are separately tailored from early levels to individual motor modalities. Namely, the hand and eyes see the external world differently.

\section{Introduction}

In exploring how the brain analyzes visual motion, numerous psychophysical and physiological studies (Burr and Ross, 1982; Johnston and Wright, 1983; Maunsell and Van Essen, 1983; Newsome and Pare, 1988; Anderson and Burr, 1991; Kawano et al., 1994; Duffy and Wurtz, 1997; Whitney and Cavanagh, 2000; Priebe and Lisberger, 2004) have focused on the specificities of perceptual performance and motion-sensitive neural activities. Prevailing views on how external visual motion is encoded assume that a unified visual motion analysis is used for various brain computations for object recognition, scene perception, and motor control (Van Essen et al., 1992). In fact, many studies reported that oculomotor performance driven by visual motion is closely related to the perceived motion (Yasui and Young, 1975; Beutter and Stone, 2000; Stone and Krauzlis, 2003) and that similar forms of visual feature detection subserve different motor systems, such as the eyes, arms, and legs (Engel et al., 2000; Glover and Dixon, 2004). This parsimonious representation would be attractive in examining the brain computation because the brain may require coherent visual information representing the external physical world for its different downstream functions.

Received Oct. 6, 2012; revised Aug. 21, 2013; accepted Sept. 9, 2013.

Author contributions: H.G. designed research; H.G. and N.A. performed research; H.G. contributed unpublished reagents/analytic tools; H.G. analyzed data; H.G. and S.S. wrote the paper.

This work was supported by the ERATO Shimojo Implicit Brain Function Project, Japan Science and Technology Agency. We thank S. Nishida, T. Kimura, and D. Whitney for constructive discussions and N. Ueda, E. Maeda, and M. Kashino for support and encouragement. We also thank anonymous reviewers for valuable comments and suggestions.

Correspondence should be addressed to Hiroaki Gomi, NTT Communication Science Laboratories, Wakamiya 3-1, Morinosato, Atsugi, Kanagawa 243-0198, Japan. E-mail: gomi.hiroaki@lab.ntt.co.jp.

DOI:10.1523/JNEUROSCI.4741-12.2013

Copyright $\odot 2013$ the authors $\quad 0270-6474 / 13 / 3316502-08 \$ 15.00 / 0$
On the other hand, an alternative idea of dissociation in visual processing between action and perception has been developed on the basis of a series of experimental studies (Goodale et al., 1986; Pélisson et al., 1986; Churchland et al., 2003). The dissociation observed in a patient (Goodale et al., 1991), however, has recently been better described by a dichotomy of egocentric and allocentric processing (Schenk, 2006), and several studies carefully argued about the dissociation between action and perception (Franz et al., 2000; Smeets and Brenner, 2006). It is therefore still unclear what level of visual processing is dissociated. According to some of these discussions, the dissociation could occur in the high-level process for brain functions rather than in the low-level visual feature analysis. Actually, as for quick eye responses induced by several visual motion attributes, some of the dissociations of the response specificities from the perception specificities can be explained by different levels of motion processing, such as first-order motion and non-first-order motion detections (Guo and Benson, 1999; Masson and Castet, 2002; Hayashi et al., 2008; Hayashi et al., 2010). However, whether a low-level visual analysis extracting a particular visual attribute is distinctively processed for different brain functions has not yet been well examined.

Here we focus on the visual motion analysis for hand and eye controls in which surrounding visual motion elicits ultrashort latency responses in the direction of the visual motion (Miles et al., 1986; Kawano et al., 1994; Brenner and Smeets, 1997; Whitney et al., 2003; Saijo et al., 2005). These quick reflexive responses of the hand and eye, respectively termed the manual following response (MFR) and ocular following response (OFR), are considered to function in reducing the corresponding movement error in dynamical interactions with environments (Miles et al., 


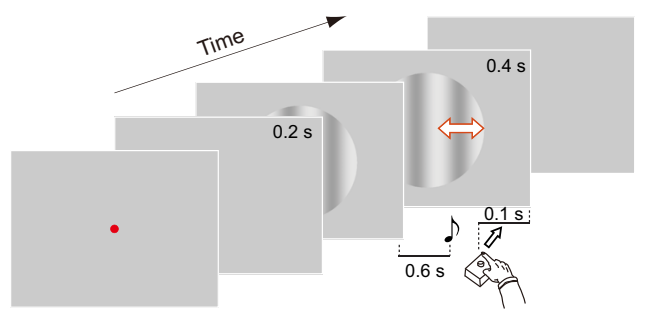

Figure 1. Temporal sequence of the task and stimulus. The visual stimulus (contrast grating pattern) appeared $0.6 \mathrm{~s}$ after the target flash (red small marker), started to move leftward or rightward $0.1 \mathrm{~s}$ after the button release, and lasted $0.4 \mathrm{~s}$. In the hand-movement blocks, subjects were instructed to make a smooth reaching movement after releasing the button and touch the location of flashed target on the screen (see Materials and Methods for details). Note that stimulus motion started just after reaching start (button release) in the hand-movement blocks.

1986; Gomi, 2008). Interestingly, the hand response has gaintuning specificities similar to those of the eye response for changes in image luminance contrast and spatiotemporal frequencies of the large-field visual motion (Gomi et al., 2006), whereas these specificities are different from those of the perceptual effects caused by visual motion (Burr and Ross, 1982; Levi and Schor, 1984; De Valois and De Valois, 1991). Because of the similar specificities of the quick hand and eye responses, it was inferred that the visual motion analysis is shared for these quick motor responses. Surprisingly, however, by varying the size and location of the stimuli, here we found that the visual analyses for the hand and eye control are dramatically distinct from each other with respect to their spatiotemporal analysis and spatial integration of visual motion.

\section{Materials and Methods}

Experimental setup. Twenty-eight subjects [ 8 for Experiment 1 (Exp. 1), 10 for Experiment 2 (Exp. 2), and 10 for Experiment 3 (Exp. 3); 21 males, all right handed, 21-39 years of age] participated in this study. None of them reported having any motor or visual disorders. The subjects had normal or corrected-to-normal visual acuity. All gave informed consent to participate in the study, which was approved by the local ethics committee.

The experimental setup for the visuomotor task was almost identical to that used in our previous experiment (Kadota and Gomi, 2010). A back-projection screen was vertically placed in front of a subject $48 \mathrm{~cm}$ from the eyes. Mean luminance values around the screen center were 46.7 $\mathrm{cd} / \mathrm{m}^{2}$. Right-hand position (around the base of the index finger) was measured by a motion-capture system (VICON MX13; Peak Performance Technologies) at $250 \mathrm{~Hz}$, and right-eye angular position was measured by an eye tracker (Eyelink II; SR Research) at $500 \mathrm{~Hz}$. Eye positions were calibrated before every eye-movement recording block. The subject's head was supported by a chin rest in all experiments. In the simultaneous recording experiment (Exp. 1), we additionally used a silicon bite bar formed for each subject to immobilize the subject's head on which the eye tracker was mounted. This setup was required to minimize noises caused by arm movement in this experiment. In Exp. 2 and Exp. 3 (described below), which examined the responses in many stimulus conditions and therefore took much longer time than Exp. 1, to reduce subjects' fatigue and frustration, a bite bar was not used. The hand and eye positions were, therefore, recorded in separate sessions to avoid eyecamera fluctuation caused by hand movements. The actual time of visual motion onset was detected by a photodiode signal as in our previous studies (Saijo et al., 2005; Gomi et al., 2006; Kadota and Gomi, 2010).

Protocol and visual stimuli. Figure 1 shows the stimulus sequence and behavioral task used in all experiments in this study. Subjects were asked to keep pushing the button-switch placed on a table $(40 \mathrm{~cm}$ in horizontal direction from the screen) with the right index finger. The subjects were also asked to keep their eyes fixated on the screen center (target position)
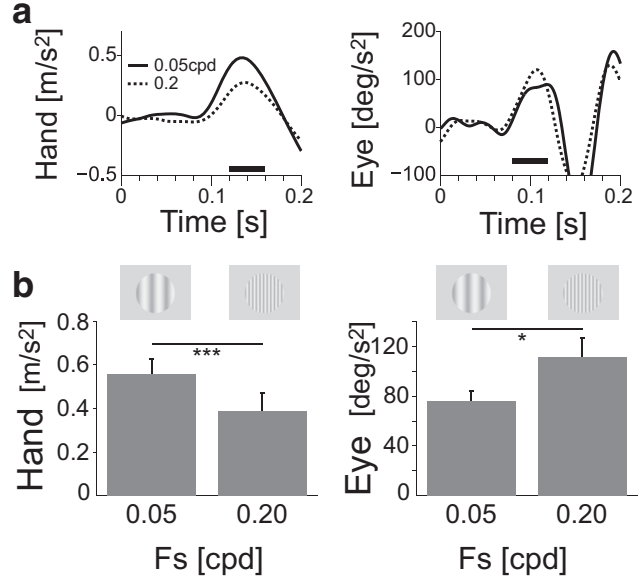

Figure 2. Difference in hand and eye responses for the two spatial frequency stimuli recorded simultaneously. $\boldsymbol{a}$, Temporal patterns of hand (left) and eye (right) responses of a particular subject to the $50^{\circ}$ stimuli with spatial frequencies of $0.05 \mathrm{cpd}$ (solid curve) and $0.2 \mathrm{cpd}$ (dashed curve) in Exp. 1. Each response was characterized by taking the difference between corresponding accelerations for rightward and leftward stimuli. Time 0 denotes the visual motion onset, and the thick black horizontal bar denotes the temporal mean duration (hand, 120-160 ms; eye, 80-120 ms) for the quantifying response amplitude. $\boldsymbol{b}$, Mean response amplitudes of the hand (left) and eye (right) for the visual motion with spatial frequencies of 0.05 and 0.2 cpd (top diagrams), respectively. Each error bar denotes the SE. Asterisks indicate statistical significance $\left({ }^{*} p<0.05 ;{ }^{* *} p<0.005\right)$ in the paired $t$ test.

and to avoid blinking until the end of each trial. While they kept pushing the button, a red target marker $(6 \mathrm{~mm})$ was flashed at the center of the screen, and one of the static grating patterns (Michelson contrast, 50\%) randomly selected from the prepared stimuli in each experiment (explained below) was shown at the center of the screen $0.2 \mathrm{~s}$ after the target flash, as shown in Figure 1. Subsequently, at $0.6 \mathrm{~s}$ after the grating pattern had appeared, a beeping sound was given to initiate hand reaching with button release (Exp. 1 and hand-reaching recording sessions in Exp. 2 and Exp. 3) or to initiate button release only (eye-movement recording sessions in Exp. 2 and Exp. 3).

In the hand-reaching recording sessions, the subjects were instructed to make a smooth reaching movement with moderate speed $(\sim 0.6 \mathrm{~s}$ for a distance of $51 \mathrm{~cm}$ from the button to the target on the screen) and touch the location of the flashed target on the screen with their index finger and to return the finger to the button on the table. The subjects were asked not to vary the reaching speed and touch position across trials, but there was no explicit feedback on the accuracy of the reaching duration and touch position during the experiment.

At $0.1 \mathrm{~s}( \pm 6 \mathrm{~ms} \mathrm{SD})$ after the button release in visual motion trials, the grating pattern started to move either rightward or leftward at a constant speed with temporal frequency of $10 \mathrm{~Hz}$, as illustrated in Figure 1. The stimulus motion continued for $0.4 \mathrm{~s}$ during hand-reaching movement. In no-visual-motion trials (the number of trials for each experiment is described below), the grating pattern was stable until the pattern vanished.

In Exp. 1, we used coarse $(0.05 \mathrm{cpd})$ and fine $(0.2 \mathrm{cpd})$ contrast grating patterns with the size of $50^{\circ}$ in diameter as visual stimuli (Fig. 2). The outside of the stimulus pattern was a gray-filled area with $50 \%$ luminance contrast. In this experiment, hand and eye movements were recorded simultaneously (360 trials in total, 80 trials for each direction of each pattern, and 20 trials for each of coarse and fine static patterns) for each subject. The order of stimuli was randomized, and an intermission was taken every 90 trials to avoid fatigue.

In Exp. 2 (center-stimulus experiment), to examine the response modulations of the hand and eye for various stimuli, we used 16 contrast grating patterns with four spatial frequencies $(0.02,0.05,0.2$, and 0.8 cpd) and four sizes of stimuli (visual angle diameters of 10,20,40, and $50^{\circ}$; Fig. 3). The outside of the stimulus pattern was a gray-filled area with $50 \%$ luminance contrast as in Exp.1. This experiment consisted of two 
hand-reaching recording sessions and two eyemovement recording sessions. In the eyemovement recording sessions, the subjects were asked to perform the same tasks without reaching movement to prevent noise in the eye position measurement, which is caused by eyetracker fluctuation accompanying arm movement without a bite bar. Instead, the subjects were asked to just release the button when they heard the beep. All trials in each of the handreaching and eye-movement recording sessions were divided into five blocks (144 trials per block). An intermission of over 5 min was inserted between blocks to avoid fatigue, and the order of hand and eye sessions were counterbalanced among subjects. In total, a grating pattern (randomly selected in each trial) moved in 1280 (40 trials for each pattern and each direction) of 1440 trials in the handreaching recording sessions. In the remaining trials, each of the 16 grating patterns (four stimulus sizes and four spatial frequencies) was kept stable in 10 trials (160 trials in total for static patterns).

In Exp. 3 (center-mask experiment), we used full-screen contrast grating patterns $[82$ $\mathrm{cm}$ (horizontal) $\times 62 \mathrm{~cm}$ (vertical); $81 \times 65.7^{\circ}$; $0.02,0.05,0.2$, and $0.8 \mathrm{cpd}$ ] with circular gray masks ( $50 \%$ luminance contrast; diameters of $0,10,20,40$, and $50^{\circ}$; Fig. 4). The procedure of this experiment, except for the stimulus patterns and number of trials, was identical to that of Exp. 2. Each block of hand or eye session consisted of 180 trials. In total, a grating pattern moved in 1600 (40 trials for each pattern and each direction) of 1800 trials for each of hand and eye sessions. In the remaining trials, each of the 20 grating patterns (five mask sizes and four spatial frequencies) was kept stable in 10 trials (200 trials in total for static patterns).

Data analysis. All captured hand and eye po-

sitions were filtered (third-order Butterworth low-pass filter with the cutoff of $20 \mathrm{~Hz}$ ), and the velocity and acceleration profiles were obtained by three- and five-point numerical time differentiations (without delay), respectively.

All data were aligned with respect to the visual motion onset. The hand and eye (right) responses caused by the visual motion were characterized by taking the difference between the corresponding time courses of mean acceleration in the horizontal direction parallel to the screen for the rightward and leftward moving conditions. Note that the mean was taken after failed trials had been excluded (no or delayed reaching, eyes closed, saccades, and missed recordings), as done in our previous studies (Kadota and Gomi, 2010). Response amplitudes were quantified by temporal averaging over a period of $120-160 \mathrm{~ms}$ for the hand acceleration profiles and $80-120 \mathrm{~ms}$ for the eye acceleration profiles after the visual motion onset. Statistical examinations for the hand and eye data in each experiment were conducted by a two-way repeated-measures ANOVA with stimulus (or mask) size and spatial frequency as factors. Post hoc comparisons (Tukey-Wholly Significant Difference test) were also applied if each factor or interaction was significant in the ANOVA.

\section{Results}

Mean hand movement durations across subjects (detected by the threshold of $0.05 \mathrm{~m} / \mathrm{s}$ ) for the simultaneous recording experiment (Exp. 1), center-stimulus experiment (Exp. 2), and center-mask experiment (Exp. 3) were $0.60 \mathrm{~s}$ ( $\pm 0.08 \mathrm{SD}$ ), $0.58 \mathrm{~s}$ ( $\pm 0.08 \mathrm{SD}$ ), and $0.56 \mathrm{~s}$ ( $\pm 0.08 \mathrm{SD})$, respectively, and there was no significant differ- ence in hand-reaching duration in the three experiments (one-way ANOVA, $p>0.6$ ).

In the first experiment, the subjects $(n=8)$ were asked to repetitively produce arm-reaching movements to a remembered target position, and the pattern shown just before reaching start suddenly began to move leftward or rightward during arm reaching (see Materials and Methods for details). As a result of the application of visual motion, the hand path is shortly curved (Saijo et al., 2005; Gomi et al., 2006) and the eye quickly moves (Miles et al., 1986; Kawano et al., 1994) in the direction of the visual motion without any action intention.

Figure $2 a$ shows the mean temporal patterns of hand and eye responses in the direction parallel to the visual motion simultaneously recorded for a particular subject. Note that these patterns were characterized by the difference in the acceleration patterns for the rightward and leftward stimuli, as done in our previous studies (Saijo et al., 2005; Gomi et al., 2006; Kadota and Gomi, 2010). Interestingly, the peak of the hand response appeared to be greater for the $0.05 \mathrm{cpd}$ stimulus than for the $0.2 \mathrm{cpd}$ stimulus, whereas the initial peak of the eye response was slightly greater for the $0.2 \mathrm{cpd}$ stimulus. Figure $2 b$ shows the amplitudes of the corresponding responses quantified by temporal averaging around each peak (see Materials and Methods). The differences between response amplitudes for the two stimuli in the hand and eye were 

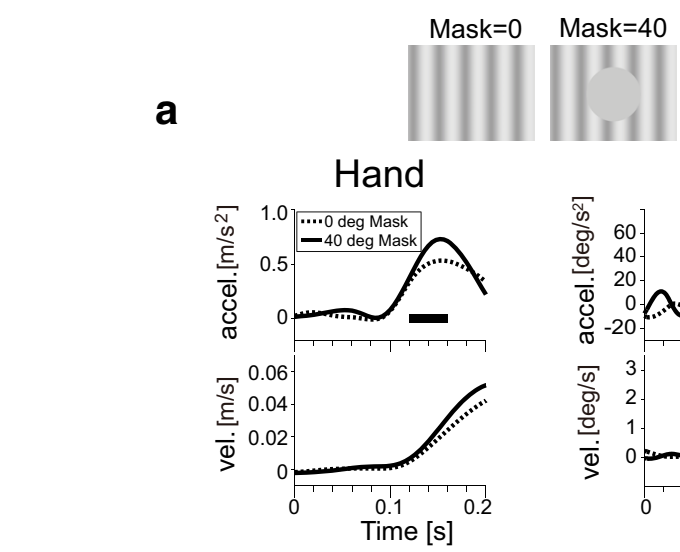
تص
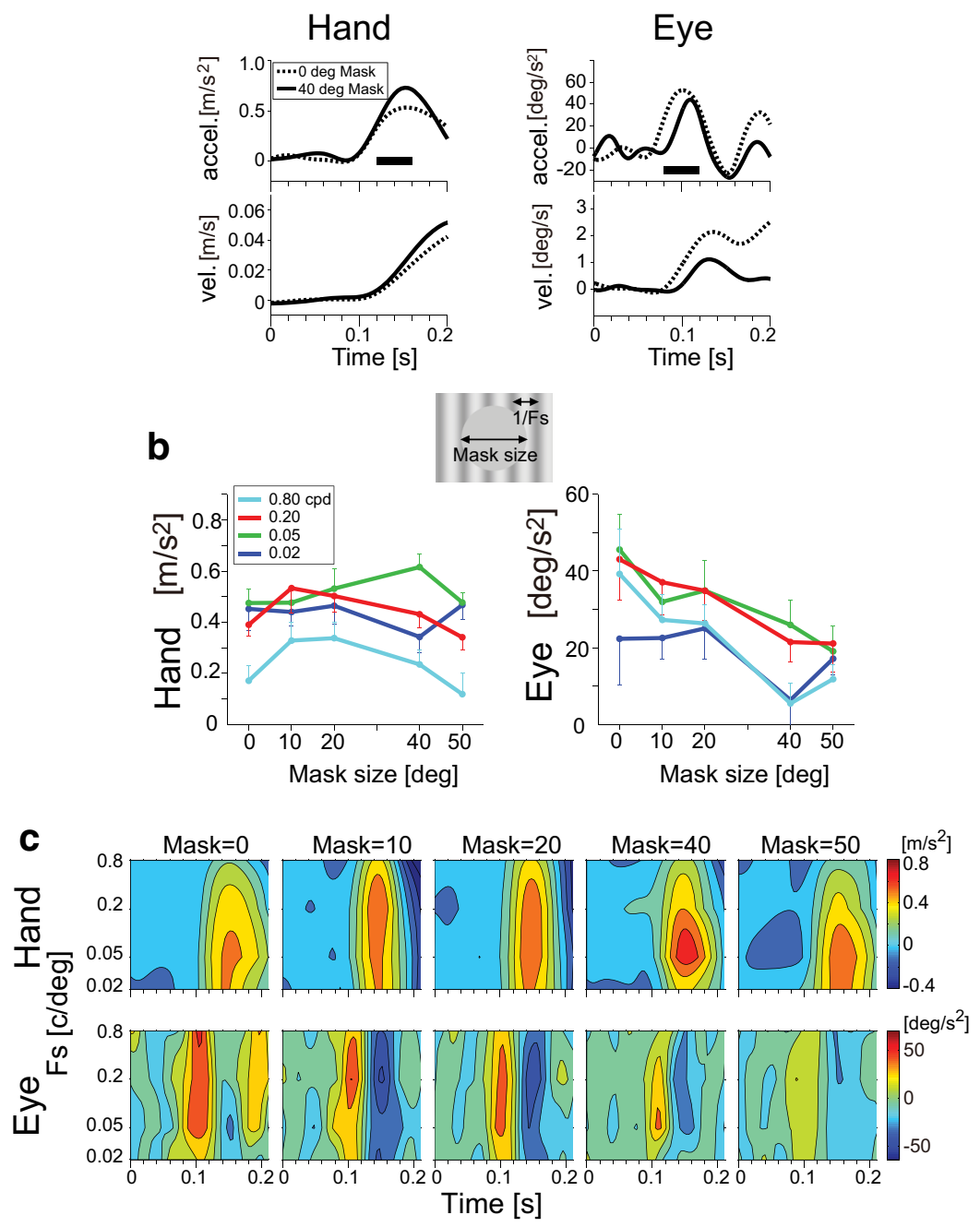

Figure 4. Hand and eye response changes for various center-masked stimuli. $\boldsymbol{a}$, Acceleration and velocity temporal patterns of hand (left) and eye (right) responses (rightward stimulus - leftward stimulus) for 0.05 cpd grating stimuli with $0^{\circ}$ (dotted curve) and $40^{\circ}$ (solid curve) masks (illustrated at the top middle), averaged across subjects. $\boldsymbol{b}$, Mask-size tunings of hand (left) and eye (right) response amplitudes for different spatial frequencies. Statistical analyses indicate that the eye response significantly decreased with mask size for all spatial frequencies but the hand response did not, especially for the 0.05 cpd stimuli (see Results). c, Temporal developments of spatial frequency tunings of hand and eye responses for the mask stimuli with the size of $0,10,20,40$ and $50^{\circ}$.

statistically significant across subjects, suggesting distinct visual motion analyses for the hand and eye controls.

To investigate in more detail the differences in the visual motion processing for the hand and eye control, we applied grating pattern stimuli with four different sizes and four spatial frequencies $\left(10,20,40\right.$, and $50^{\circ}$ of stimulus diameter; 0.02, 0.05, 0.2, and $0.8 \mathrm{cpd} ; 10 \mathrm{~Hz}$ ) in the next experiment (Exp. 2). As expected from the spatial summation principle of visual motion perception (Anderson and Burr, 1991), the hand and eye responses gradually increased with stimulus size for the lower spatial frequency stimuli (blue for 0.02 and green for $0.05 \mathrm{cpd}$ of size tuning functions; Fig. $3 a$, left). For the higher spatial frequency stimuli (red for 0.2 and cyan for $0.8 \mathrm{cpd}$ ), however, the hand response did not increase as stimulus size increased, whereas the eye response continuously increased. The interaction between the size and spatial frequency factors as well as those factors' main effects was statis- tically significant for the hand $(p<0.001$ for all three; see Materials and Methods), whereas the interaction was not for the eye (two main factors, $p<0.001$; interaction, $p>0.9)$. As a result, the opposite tendencies of the hand and eye response amplitudes for the 0.05 and $0.2 \mathrm{cpd}$ stimuli in the large stimulus conditions (Stim size of 40 and $50^{\circ}$; Fig. $3 a$ ) were similar to those observed in Exp. 1 (Fig. 2b), indicating that the eye response tuning is independent of the hand movement execution. This independency is consistent with a previous observation in which the eye response induced by visual motion was not influenced by the hand movement direction (Abekawa and Gomi, 2010).

To examine whether this tuning difference was caused by a trial adaptation in this experiment, we compared these stimulus tuning specificities for the data of the first and second half of the sessions. The interaction between the size and spatial frequency factors was consistently found both in the first and second half for the hand response ( $p<0.001$ for both), whereas no interaction was found for the eye response. It is therefore unlikely that the tuning differences between the hand and eye responses were formed by adaptation in many trials in the tasks.

Figure $3 b$ shows the temporal development (abscissa) of spatial frequency tunings (ordinate) of the hand and eye responses for stimulus sizes of $10-50^{\circ}$. As shown in Figure $3 b$ (top), the peaks (dark red) of spatial frequency tuning for the hand response for the smaller stimuli (10 and $20^{\circ}$ ) were located at $0.2 \mathrm{cpd}$, whereas those for the larger stimuli (40 and $50^{\circ}$ ) were at $0.05 \mathrm{cpd}$ without changes in the temporal timings of these peaks. In contrast, the difference between the spatial frequency tuning peaks for the smaller stimuli and larger stimuli was not observed in the eye responses, as shown in Figure $3 b$ (bottom), because the eye responses were greatest at the $0.2 \mathrm{cpd}$ at each stimulus size (Fig. $3 a$, right). This tuning dissociation between the hand and eye responses suggests a different spatial integration of visual motion for quick responses induced by visual motion in these two motor systems.

What sort of difference in the spatial integration mechanism produced these distinct visual motion analyses for different motor systems? One plausible explanation of the above phenomena is that spatial integration of visual motion with higher spatial frequency for the hand motor system is restricted within the visual center region only. To examine this simple area-integration model, we conducted another experiment (Exp. 3) in which contrast grating motion was applied with visual center masks of different sizes.

Figure $4 a$ (bottom) shows hand (left) and eye (right) responses averaged across subjects for the two stimulus patterns 
depicted at the top: the grating motions of $0.05 \mathrm{cpd}$ with the visual center masks of 0 and $40^{\circ}$. The responses for these two stimuli are depicted by solid and dotted curves, respectively. Surprisingly, the hand acceleration peak did not decrease but, rather, appeared to slightly increase with the $40^{\circ}$ masking of the stimulus center, whereas the initial increases of eye acceleration and resultant eye velocity were markedly delayed and reduced.

To examine the tendencies in response modulations, we plotted the mask-size tuning functions (mask size, $0-50^{\circ}$ ) of the hand and eye responses to the visual motions at each spatial frequency, as shown in Figure $4 b$. Although the eye response amplitude (Figure $4 b$, right $)$ significantly decreased with mask size $(p<0.0001)$, the hand response amplitude (Figure $4 b$, left) did not show such a monotonic decrease with mask size [significant interaction $(p<0.05)$ between two main factors; significant changes $(p<$ 0.05 ) in hand response only for 0.2 and $0.8 \mathrm{cpd}$ in post hoc analyses]. As demonstrated in Figure $4 a$, even with the $40^{\circ}$ visual center mask, a clear hand response was observed for the $0.05 \mathrm{cpd}$ stimulus (Fig. $4 b$, left, green curve), and, surprisingly, it was slightly greater (one-sided paired $t$ test, $p<0.05$ ) than that with the no $\left(0^{\circ}\right)$ visual center mask.

To examine the trial adaptation effect on the stimulus tuning specificities, we also analyzed the data of the first and second half of all sessions of the center-mask experiment. As observed in the above analyses, the eye response decreased with mask size both in the first and second half (size main effect, $p<0.05$ for both) and hand response did not, especially for the spatial frequency of 0.05 cpd, suggesting that trial adaptation in this experiment is less relevant in characterizing the difference between the hand and eye responses, as examined for the data of Exp. 2.

Additionally, for the higher spatial frequencies (0.2 and 0.8 cpd), the response was clearly induced $(t$ test, $p<0.005)$ with the 10 and $20^{\circ}$ masks (Fig. $4 b$, left, red and cyan curves), although in the center-stimulus experiment shown above (Fig. $3 a$, left), the response for 0.2 and $0.8 \mathrm{cpd}$ stimuli (red and cyan lines) was not increased significantly (ANOVA, $p>0.5$ ) by expanding the stimulus area over $10^{\circ}$. Furthermore, small masks $\left(10\right.$ and $\left.20^{\circ}\right)$ appeared to magnify the hand responses for the stimuli with higher spatial frequency ( 0.2 and $0.8 \mathrm{cpd}$ ) despite the reduction of stimulus area.

These response increases caused by removing the visual center stimulus suggest a disinhibition from center to peripheral motion coding. As a result of these spatial interactions, spatial frequency tunings varied with mask size as shown in Figure $4 c$. In the tunings of the hand (Figure $4 c$, top), a relatively low spatial frequency peak was observed in the 0,40 , and $50^{\circ}$ mask conditions at around $140 \mathrm{~ms}$, whereas such strong specificity was not observed in the 10 and $20^{\circ}$ mask conditions. These observations negate the above-mentioned simple area-integration model for the hand control. Instead, the results suggest spatial (inhibitory) interactions between the visual center and periphery in integrating spatially distributed visual motion signals. On the other hand, in the eye response shown in Figure $4 c$ (bottom), the peak of spatial frequency tuning appeared to be monotonically shifted to a lower spatial frequency with mask size, accompanied by a decrease in the peak amplitude.

\section{Discussion}

\section{Distinct visual motion analyses for the hand and eye}

The current results shed light on the spatial frequency- and stimulus-size-dependent modulation of visual motion analyses involved in the quick visuomotor controls for the hand and eye. Although similar spatial frequency tunings for the quick hand and eye responses were found for the small stimuli (Stim size of 10 and $20^{\circ}$; Fig. $4 b$ ) in the current study and for the large and low-contrast stimuli (Gomi et al., 2006), different specificities of the stimulus-size and mask-size tunings were newly found for the hand and eye responses by examining the various types of stimuli. To dissociate these tunings, a subset of visual motion signals over the visual field needs to be integrated differently for the hand and eye. This suggests distinct processing for the visual motion although its neural implementation cannot yet be ascertained only from the current results. Note that since the specificities of spatiotemporal frequency tunings of the hand and eye responses (tuning peak at around $\sim 15-20 \mathrm{~Hz}$ with $\sim 0.05 \mathrm{cpd}$ for relatively large size stimulus) (Gomi et al., 2006) are completely different from those of the known visual interaction effects of induced position shift (tuning peak at around $4-8 \mathrm{~Hz}$ with low spatial frequency) (De Valois and De Valois, 1991) and induced motion (tuning peak of induction ratio at $<1 \mathrm{~Hz}$ with $\sim 1-5 \mathrm{cpd}$ ) (Levi and Schor, 1984), it is unlikely that this dissociation can be explained by the different visual attributes: one motor response is driven by an illusory position shift of the grating stimulus and the other is by the direct effect of visual motion.

In the second experiment, the most prominent difference in the hand response tunings from the eyes was the insignificant response increase with stimulus size for the higher spatial frequencies (Fig. 3a). One could speculate that this absence of an increase in the hand responses is attributable to a ceiling effect on the motor response. This is, however, unlikely because the response amplitudes for the stimuli with higher spatial frequency appeared to be still smaller than the response for the $50^{\circ}$ stimulus with $0.05 \mathrm{cpd}$ (Fig. 2b). Another possible reason could be a sparse spatial integration of the higher spatial frequency visual motion in the visual periphery because the neuron population is low in peripheral vision (Rolls and Cowey, 1970; Rovamo et al., 1978; Johnston and Wright, 1983). However, if we assume a unified visual motion analysis, this idea cannot explain our observation that the amplitude of the eye response increased with stimulus size similarly for all spatial frequency stimuli (Fig. $3 a$, right).

One could also speculate that the stimulus-tuning difference between the hand and eye responses is caused by the temporally delayed sampling of the hand response compared with that for the eye response, as can be seen in Figure $2 a$. However, as shown in the temporal development of spatial frequency tunings of the hand response (Fig. 3b), the tuning-peak timings seemed not to be different among all the stimulus sizes. Therefore, the longer temporal delay of the hand response $(30-40 \mathrm{~ms})$ than that of the eye would be simply attributable to the longer neural transmission/processing time and the large inertial dynamics of the arm (Saijo et al., 2005). In addition, considering that the retinal slip changed by an initial eye response affects the successive eye and hand responses after $\sim 160 \mathrm{~ms}$ (since latency of eye response was $\sim 80 \mathrm{~ms}$ ), different specificities in stimulus tuning of the hand and eye responses shown in the results cannot be ascribed to any difference in visual motion inputs. It is therefore suggested that the visual motion processing producing the stimulus-sizedependent change in the spatial frequency tuning of the hand response is distinct from that producing the stimulus-sizeindependent change in the spatial frequency tuning of the eye.

Furthermore, the results of Exp. 3 clearly indicate spatial frequency-dependent interactions between the visual motion signals coded in the visual center and periphery for the hand control. Since simple accumulation or local interactions of motion signals over the visual field do not produce such a long-range spatial interaction (Angelucci et al., 2002), high-level visual motion pro- 
cessing stages would be involved to characterize the remote interaction. Importantly, since the mask-size tunings of the eye response were greatly different from those of the hand response, spatial interactions over visual areas would differently characterize the hand and eye responses.

A critical aspect of the above findings is that the dissociations cannot be explained by any difference in motor dynamics or in motor coordinates with a single (or completely shared) visual motion analysis. In contrast, previously reported dissociation depending on motor system (Masson et al., 1995) or depending on task context (Abekawa and Gomi, 2010; Tramper and Gielen, 2011) can be ascribed to different motor coordination processes for eye and hand controls (i.e., motor planning, motor command generation, or eye-hand coupling), rather than the distinct visual processes. The dissociation found in our study is, therefore, essential in proving multiple streams of visual motion processing for different motor functions.

\section{Functional significance of motor-dependent visual motion analysis}

The two sharp contrasts in the stimulus-size and mask-size tunings of hand and eye responses provide a new functional insight into the visual motion analysis. Since vestibular information greatly contributes to, but is still insufficient to, adjust hand reaching against body movements (Blouin et al., 1995a,b; Whitney et al., 2003), this peripheral-weighted visual motion analysis would be useful for improving the dynamic performance of the hand-reaching control during the body motion that frequently accompanies a large-field visual motion (Whitney et al., 2003; Gomi, 2008). In other words, the motion of a course pattern detected at the visual periphery would usually reflect body motion. This is in agreement with the body posture control that is also sensitive to a stimulus on the visual periphery (Brandt et al., 1973; Lestienne et al., 1977; Straube et al., 1994). In contrast, relatively higher spatial frequency and visual-center-weighted tuning in the eye response would be functional in stabilizing retinal images on the foveal and parafoveal regions, which are important in capturing gazed objects. Even though the observed ultraquick hand and eye responses were small and transient in the current experimental setup to strictly focus on the straightforward effect of visual motion, they might be continuously used in the dynamic controls in daily life. Distinct tuning of visual motion integration for each motor system would, therefore, be quite meaningful and functional for improving each motor performance.

Traditional visual neuroscience studies have tackled the question of how visual attributes are decomposed and represented in different neural substrates (Zeki, 1978; Van Essen et al., 1992), and it has been widely believed that each decomposed feature is commonly used in various brain functions, such as perception and controls in different motor systems. Actually, as mentioned in the introduction, similar forms of visual motion analyses would be involved in a particular type of oculomotor control and motion perception (Yasui and Young, 1975; Beutter and Stone, 2000; Stone and Krauzlis, 2003). On the other hand, several studies suggested multiple visual processing according to each downstream function (Goodale et al., 1986; Pélissonet al., 1986; Churchland et al., 2003), and recent studies have revealed that visual motion is coded in several brain areas, which, as described below, could contribute to different output functions. Our results provide quantitative evidence that visual motion coding is differently formed according to particular downstream motor functions, i.e., quick hand and eye controls. For a deeper under- standing of the hierarchical and parallel brain processing, we need to reconsider the overly simplified representation of visual attributes in the brain.

\section{Possible neural substrates contributing to distinct visual motion analyses}

Together, the current results therefore predict that different neural substrates are involved in the visual motion analyses for the hand and eye controls. As mentioned in the introduction, physiological and functional brain imaging techniques associated with eye movements and visual motion perception have examined the contribution of motion-specific areas in the extrastriate cortex [middle temporal area (MT/V5) and medial superior temporal area (MST)] (Maunsell and Van Essen, 1983; Komatsu and Wurtz, 1988; Newsome and Pare, 1988; Graziano et al., 1994; Kawano et al., 1994; Duffy and Wurtz, 1997; Priebe and Lisberger, 2004) to the visual motion analysis. These studies successfully demonstrated many features of neural activities in the MT/ MST for the various stimuli (speed preference, receptive field size/location, spatiotemporal frequency tunings, and latency) but did not suggest any idea that distinct spatial integration of visual motion is characterized for each motor system. Even though the visual motion signals coded in area MST drives the quick OFR (Kawano et al., 1994; Takemura et al., 2007), a different population of MT/MST neurons could be involved in the visual motion analysis for the MFR. Actually, we found a significant correlation between the blood oxygen level-dependent signal around hMT+ and MFR amplitude in our fMRI experiment (Gomi et al., 2011) and found that the inactivation of monkey MST by muscimol injection leads to the MFR reduction (Takemura et al., 2008). In addition, the dorsal part of MST has connections to the area 7b (Andersen et al., 1990; Boussaoud et al., 1990), which could send signals to the primary motor cortex via the ventral part of the premotor area (Shipp et al., 1998). These facts encourage the possibility of contribution of the MT/MST to the MFR generation.

On the other hand, it has been found that occipito-parietal areas are also involved in the global motion analysis (Galletti et al., 1990; Watson et al., 1993; Dupont et al., 1994; Cheng et al., 1995; Gegenfurtner et al., 1997; Tootell et al., 1997; Smith et al., 1998; Sunaert et al., 1999; Braddick et al., 2001; Vanduffel et al., 2002; Orban et al., 2003; Fischer et al., 2012). These areas could therefore provide different or additional spatial integration characteristics suitable for quick hand control.

The area V6 receives visual signals from the early visual cortexes (V1, V2, V3, V3A) (Galletti et al., 2001), and many neurons are activated by the motion stimuli with various speeds (Galletti et al., 2001) and by peripheral visual field stimuli (Galletti et al., 1999; Pitzalis et al., 2006), in conjunction with the other motionsensitive area, MT/MST (Galletti et al., 2001). In addition, it is suggested that V6, as well as the area MST, is involved in the self-motion analysis (Cardin and Smith, 2010). Furthermore, V6 is strongly connected to $\mathrm{V} 6 \mathrm{~A}$, which is reciprocally connected to the dorsal premotor cortex (Matelli et al., 1998; Shipp et al., 1998; Fattori et al., 2005). Considering these facts, V6 could be involved in the MFR generation process. As far as we know, however, motion spatiotemporal frequency tunings of the V6 neurons and the stimulus-size dependency of those tunings are not clearly understood yet.

As for the other motion-sensitive area, $\mathrm{V} 3 \mathrm{~A}$, the receptive field sizes [e.g., $6^{\circ}$ in monkey at eccentricity of $14^{\circ}$ (Galletti et al., $1990)$; $\sim 10^{\circ}$ at human peripheral visual field of eccentricity of $\sim 12^{\circ}$ (Smith et al., 2001; Amano et al., 2009)] are smaller than 
those of neurons in V6 (Galletti et al., 1999) and MST (Komatsu and Wurtz, 1988), but an fMRI experiment showed that V3A is vigorously activated by coherent motion (Braddick et al., 2001) and even by large stimuli (Cardin and Smith, 2010). Since, in the current study, MFR was clearly induced by the relatively small $\left(10^{\circ}\right)$ stimulus with higher spatial frequency $(0.2$ or $0.8 \mathrm{cpd})$, area V3A could be involved in the MFR generation process for these small stimuli.

Additional evidence would be needed to clarify whether either or both V6 and MT/MST contribute to the MFR. Clarifying the neural substrates for the MFR, it would be at least required to examine (1) the details of the specificities of the neural activities for various stimuli (spatiotemporal-frequency tunings, stimulussize spatial frequency tunings, and latencies of neural activity to stimuli) and (2) the effects of focal inactivation or damage of V6 and MST on the MFR. Our findings indicating the motordependent visual motion analyses would provide new insights for precisely investigating the neural substrates that process the visual motion for each motor function.

\section{References}

Abekawa N, Gomi H (2010) Spatial coincidence of intentional actions modulates an implicit visuomotor control. J Neurophysiol 103:2717-2727. CrossRef Medline

Amano K, Wandell BA, Dumoulin SO (2009) Visual field maps, population receptive field sizes, and visual field coverage in the human MT+ complex. J Neurophysiol 102:2704-2718. CrossRef Medline

Andersen RA, Asanuma C, Essick G, Siegel RM (1990) Corticocortical connections of anatomically and physiologically defined subdivisions within the inferior parietal lobule. J Comp Neurol 296:65-113. CrossRef Medline

Anderson SJ, Burr DC (1991) Spatial summation properties of directionally selective mechanisms in human vision. J Opt Soc Am A 8:1330-1339. CrossRef Medline

Angelucci A, Levitt JB, Walton EJ, Hupe JM, Bullier J, Lund JS (2002) Circuits for local and global signal integration in primary visual cortex. J Neurosci 22:8633-8646. Medline

Beutter BR, Stone LS (2000) Motion coherence affects human perception and pursuit similarly. Vis Neurosci 17:139-153. Medline

Blouin J, Gauthier GM, Vercher JL (1995a) Failure to update the egocentric representation of the visual space through labyrinthine signal. Brain Cogn 29:1-22. CrossRef Medline

Blouin J, Gauthier GM, van Donkelaar P, Vercher JL (1995b) Encoding the position of a flashed visual target after passive body rotations. Neuroreport 6:1165-1168. CrossRef Medline

Boussaoud D, Ungerleider LG, Desimone R (1990) Pathways for motion analysis: cortical connections of the medial superior temporal and fundus of the superior temporal visual areas in the macaque. J Comp Neurol 296:462-495. CrossRef Medline

Braddick OJ, O'Brien JM, Wattam-Bell J, Atkinson J, Hartley T, Turner R (2001) Brain areas sensitive to coherent visual motion. Perception 30:6172. CrossRef Medline

Brandt T, Dichgans J, Koenig E (1973) Differential effects of central verses peripheral vision on egocentric and exocentric motion perception. Exp Brain Res 16:476-491. Medline

Brenner E, Smeets JB (1997) Fast responses of the human hand to changes in target position. J Mot Behav 29:297-310. CrossRef Medline

Burr DC, Ross J (1982) Contrast sensitivity at high velocities. Vision Res 22:479-484. CrossRef Medline

Cardin V, Smith AT (2010) Sensitivity of human visual and vestibular cortical regions to egomotion-compatible visual stimulation. Cereb Cortex 20:1964-1973. CrossRef Medline

Cheng K, Fujita H, Kanno I, Miura S, Tanaka K (1995) Human cortical regions activated by wide-field visual motion: an $\mathrm{H} 2(15) \mathrm{O}$ PET study. J Neurophysiol 74:413-427. Medline

Churchland AK, Gardner JL, Chou IH, Priebe NJ, Lisberger SG (2003) Directional anisotropies reveal a functional segregation of visual motion processing for perception and action. Neuron 37:1001-1011. CrossRef Medline

De Valois RL, De Valois KK (1991) Vernier acuity with stationary moving Gabors. Vision Res 31:1619-1626. CrossRef Medline
Duffy CJ, Wurtz RH (1997) Multiple temporal components of optic flow responses in MST neurons. Exp Brain Res 114:472-482. CrossRef Medline

Dupont P, Orban GA, De Bruyn B, Verbruggen A, Mortelmans L (1994) Many areas in the human brain respond to visual motion. J Neurophysiol 72:1420-1424. Medline

Engel KC, Anderson JH, Soechting JF (2000) Similarity in the response of smooth pursuit and manual tracking to a change in the direction of target motion. J Neurophysiol 84:1149-1156. Medline

Fattori P, Kutz DF, Breveglieri R, Marzocchi N, Galletti C (2005) Spatial tuning of reaching activity in the medial parieto-occipital cortex (area V6A) of macaque monkey. Eur J Neurosci 22:956-972. CrossRef Medline

Fischer E, Bülthoff HH, Logothetis NK, Bartels A (2012) Human areas V3A and V6 compensate for self-induced planar visual motion. Neuron 73: 1228-1240. CrossRef Medline

Franz VH, Gegenfurtner KR, Bülthoff HH, Fahle M (2000) Grasping visual illusions: no evidence for a dissociation between perception and action. Psychol Sci 11:20-25. CrossRef Medline

Galletti C, Battaglini PP, Fattori P (1990) "Real-motion" cells in area V3A of macaque visual cortex. Exp Brain Res 82:67-76. CrossRef Medline

Galletti C, Fattori P, Gamberini M, Kutz DF (1999) The cortical visual area V6: brain location and visual topography. Eur J Neurosci 11:3922-3936. CrossRef Medline

Galletti C, Gamberini M, Kutz DF, Fattori P, Luppino G, Matelli M (2001) The cortical connections of area $\mathrm{V} 6$ : an occipito-parietal network processing visual information. Eur J Neurosci 13:1572-1588. CrossRef Medline

Gegenfurtner KR, Kiper DC, Levitt JB (1997) Functional properties of neurons in macaque area V3. J Neurophysiol 77:1906-1923. Medline

Glover S, Dixon P (2004) A step and a hop on the Muller-Lyer: illusion effects on lower-limb movements. Exp Brain Res 154:504-512. CrossRef Medline

Gomi H (2008) Implicit online corrections of reaching movements. Curr Opin Neurobiol 18:558-564. CrossRef Medline

Gomi H, Abekawa N, Nishida S (2006) Spatiotemporal tuning of rapid interactions between visual-motion analysis and reaching movement. J Neurosci 26:5301-5308. CrossRef Medline

Gomi H, Chib VS, Aso T, Shimojo S (2011) Manual following response induced by visual motion during reaching movements is mediated by extrastriate cortex. Soc Neurosci Abstr 37:852.810.

Goodale MA, Pelisson D, Prablanc C (1986) Large adjustments in visually guided reaching do not depend on vision of the hand or perception of target displacement. Nature 320:748-750. CrossRef Medline

Goodale MA, Milner AD, Jakobson LS, Carey DP (1991) A neurological dissociation between perceiving objects and grasping them. Nature 349: 154-156. CrossRef Medline

Graziano MS, Andersen RA, Snowden RJ (1994) Tuning of MST neurons to spiral motions. J Neurosci 14:54-67. Medline

Guo K, Benson PJ (1999) Grating and plaid chrominance motion influences the suppressed ocular following response. Neuroreport 10:387-392. CrossRef Medline

Hayashi R, Miura K, Tabata H, Kawano K (2008) Eye movements in response to dichoptic motion: evidence for a parallel-hierarchical structure of visual motion processing in primates. J Neurophysiol 99:2329-2346. CrossRef Medline

Hayashi R, Sugita Y, Nishida S, Kawano K (2010) How motion signals are integrated across frequencies: study on motion perception and ocular following responses using multiple-slit stimuli. J Neurophysiol 103:230 243. CrossRef Medline

Johnston A, Wright MJ (1983) Visual motion and cortical velocity. Nature 304:436-438. CrossRef Medline

Kadota K, Gomi H (2010) Implicit visuomotor processing for quick online reactions is robust against aging. J Neurosci 30:205-209. CrossRef Medline

Kawano K, Shidara M, Watanabe Y, Yamane S (1994) Neural activity in cortical area MST of alert monkey during ocular following responses. J Neurophysiol 71:2305-2324. Medline

Komatsu H, Wurtz RH (1988) Relation of cortical areas MT and MST to pursuit eye movements. I. Localization and visual properties of neurons. J Neurophysiol 60:580-603. Medline

Lestienne F, Soechting J, Berthoz A (1977) Postural readjustments induced by linear motion of visual scenes. Exp Brain Res 28:363-384. Medline 
Levi DM, Schor CM (1984) Spatial and velocity tuning of processes underlying induced motion. Vision Res 24:1189-1195. CrossRef Medline

Masson GS, Castet E (2002) Parallel motion processing for the initiation of short-latency ocular following in humans. J Neurosci 22:5149-5163. Medline

Masson G, Proteau L, Mestre DR (1995) Effects of stationary and moving textured backgrounds on the visuo-oculo-manual tracking in humans. Vision Res 35:837-852. CrossRef Medline

Matelli M, Govoni P, Galletti C, Kutz DF, Luppino G (1998) Superior area 6 afferents from the superior parietal lobule in the macaque monkey. J Comp Neurol 402:327-352. CrossRef Medline

Maunsell JH, Van Essen DC (1983) Functional properties of neurons in middle temporal visual area of the macaque monkey. I. Selectivity for stimulus direction, speed, and orientation. J Neurophysiol 49:1127-1147. Medline

Miles FA, Kawano K, Optican LM (1986) Short-latency ocular following responses of monkey: I. Dependence on temporospatial properties of visual input. J Neurophysiol 56:1321-1354. Medline

Newsome WT, ParéEB (1988) A selective impairment of motion perception following lesions of the middle temporal visual area (MT). J Neurosci 8:2201-2211. Medline

Orban GA, Fize D, Peuskens H, Denys K, Nelissen K, Sunaert S, Todd J, Vanduffel W (2003) Similarities and differences in motion processing between the human and macaque brain: evidence from fMRI. Neuropsychologia 41:1757-1768. CrossRef Medline

PélissonD, Prablanc C, Goodale MA, Jeannerod M (1986) Visual control of reaching movements without vision of the limb. II. Evidence of fast unconscious processes correcting the trajectory of the hand to the final position of a double-step stimulus. Exp Brain Res 62:303-311. Medline

Pitzalis S, Galletti C, Huang RS, Patria F, Committeri G, Galati G, Fattori P, Sereno MI (2006) Wide-field retinotopy defines human cortical visual area v6. J Neurosci 26:7962-7973. CrossRef Medline

Priebe NJ, Lisberger SG (2004) Estimating target speed from the population response in visual area MT. J Neurosci 24:1907-1916. CrossRef Medline

Rolls ET, Cowey A (1970) Topography of the retina and striate cortex and its relationship to visual acuity in rhesus monkeys and squirrel monkeys. Exp Brain Res 10:298-310. Medline

Rovamo J, Virsu V, NäsänenR (1978) Cortical magnification factor predicts the photopic contrast sensitivity of peripheral vision. Nature 271:54-56. CrossRef Medline

Saijo N, Murakami I, Nishida S, Gomi H (2005) Large-field visual motion directly induces an involuntary rapid manual following response. J Neurosci 25:4941-4951. CrossRef Medline

Schenk T (2006) An allocentric rather than perceptual deficit in patient D.F. Nat Neurosci 9:1369-1370. CrossRef Medline

Shipp S, Blanton M, Zeki S (1998) A visuo-somatomotor pathway through superior parietal cortex in the macaque monkey: cortical connections of areas V6 and V6A. Eur J Neurosci 10:3171-3193. CrossRef Medline
Smeets JB, Brenner E (2006) 10 years of illusions. J Exp Psychol Hum Percept Perform 32:1501-1504. CrossRef Medline

Smith AT, Greenlee MW, Singh KD, Kraemer FM, Hennig J (1998) The processing of first- and second-order motion in human visual cortex assessed by functional magnetic resonance imaging (fMRI). J Neurosci 18:3816-3830. Medline

Smith AT, Singh KD, Williams AL, Greenlee MW (2001) Estimating receptive field size from fMRI data in human striate and extrastriate visual cortex. Cereb Cortex 11:1182-1190. CrossRef Medline

Stone LS, Krauzlis RJ (2003) Shared motion signals for human perceptual decisions and oculomotor actions. J Vis 3:725-736. CrossRef Medline

Straube A, Krafczyk S, Paulus W, Brandt T (1994) Dependence of visual stabilization of postural sway on the cortical magnification factor of restricted visual fields. Exp Brain Res 99:501-506. Medline

Sunaert S, Van Hecke P, Marchal G, Orban GA (1999) Motion-responsive regions of the human brain. Exp Brain Res 127:355-370. CrossRef Medline

Takemura A, Murata Y, Kawano K, Miles FA (2007) Deficits in shortlatency tracking eye movements after chemical lesions in monkey cortical areas MT and MST. J Neurosci 27:529-541. CrossRef Medline

Takemura A, Ofuji T, Abekawa N, Kawano K, Gomi H (2008) Short-latency manual responses of monkey are impaired by lesions in the MST. Soc Neurosci Abstr 34:262.214.

Tootell RB, Mendola JD, Hadjikhani NK, Ledden PJ, Liu AK, Reppas JB, Sereno MI, Dale AM (1997) Functional analysis of V3A and related areas in human visual cortex. J Neurosci 17:7060-7078. Medline

Tramper JJ, Gielen CC (2011) Visuomotor coordination is different for different directions in three-dimensional space. J Neurosci 31:7857-7866. CrossRef Medline

Vanduffel W, Fize D, Peuskens H, Denys K, Sunaert S, Todd JT, Orban GA (2002) Extracting 3D from motion: differences in human and monkey intraparietal cortex. Science 298:413-415. CrossRef Medline

Van Essen DC, Anderson CH, Felleman DJ (1992) Information processing in the primate visual system: an integrated systems perspective. Science 255:419-423. CrossRef Medline

Watson JD, Myers R, Frackowiak RS, Hajnal JV, Woods RP, Mazziotta JC, Shipp S, Zeki S (1993) Area V5 of the human brain: evidence from a combined study using positron emission tomography and magnetic resonance imaging. Cereb Cortex 3:79-94. CrossRef Medline

Whitney D, Cavanagh P (2000) Motion distorts visual space: shifting the perceived position of remote stationary objects. Nat Neurosci 3:954-959. CrossRef Medline

Whitney D, Westwood DA, Goodale MA (2003) The influence of visual motion on fast reaching movements to a stationary object. Nature 423 : 869-873. CrossRef Medline

Yasui S, Young LR (1975) Perceived visual motion as effective stimulus to pursuit eye movement system. Science 190:906-908. CrossRef Medline

Zeki SM (1978) Functional specialisation in the visual cortex of the rhesus monkey. Nature 274:423-428. CrossRef Medline 